\title{
Upper Endoscopy in International Digestive Endoscopy Network 2012: Towards Upper End of Quality
}

\author{
II Ju Choi \\ Center for Gastric Cancer, National Cancer Center, Goyang, Korea
}

\begin{abstract}
Upper gastrointestinal (GI) endoscopy is the most basic part of endoscopy field. Although old and basic procedures are still in use, a line of innovative techniques and devices are being introduced to allow much complex and difficult procedures in endoscopy unit. High quality upper endoscopic procedures can replace or obviate surgical treatment. Selected reviews dealing with non-variceal upper GI bleeding, challenging esophageal stenting, endoscopic management of subpeithelial tumor, and endoscopic evaluation for candidate lesions of endoscopic submucosal dissection were selected among the topics from International Digestive Endoscopy Network 2012.
\end{abstract}

Key Words: Endoscopy; Hemorrhage; International Digestive Endoscopy Network

\section{INTRODUCTION}

Scientific sessions of the upper gastrointestinal (GI) tract dealt with important issues of diagnostic and therapeutic endoscopy of this field during International Digestive Endoscopy Network (IDEN) 2012 (www.iden2012.org). ${ }^{1}$ On the 1st day, opening session titled "Role of endoscopy in GERD and Barrett's esophagus" included the issues of endoscopic diagnosis and advanced imaging of the diseases, and endoscopic treatment including endoscopic submucosal dissection (ESD). In the following session titled "Endoscopy Beyond Submucosa," the topics including endoscopic diagnosis of gastrointestinal stromal tumor (GIST) by cutting and incising mucosa, various endoscopic treatments of subepithelial tumor (SET), and cutting edge technique for achalasia treatment were presented. In the third session, the estimation of invasion depth of early gastric cancer (EGC) for proper management plan using conventional endoscopy and endoscopic ultrasonography (EUS) was introduced. On the second day, first session

\section{Received: July 27, 2012 Revised: July 27, 2012}

Accepted: July 27, 2012

Correspondence: Il Ju Choi

Center for Gastric Cancer, National Cancer Center, 323 Ilsan-ro, Ilsandonggu, Goyang 410-769, Korea

Tel: +82-31-920-2282, Fax: +82-31-920-1520, E-mail: cij1224@hanmail.net

(a) This is an Open Access article distributed under the terms of the Creative Commons Attribution Non-Commercial License (http://creativecommons.org/ licenses/by-nc/3.0) which permits unrestricted non-commercial use, distribution, and reproduction in any medium, provided the original work is properly cited. titled "Issues for tailored ESD" included presentation of ESD indication based on the long-term outcome results from Korea and Japan. Also, contention on ESD for EGC with undifferentiated histology was presented. In the following session, two highlighted lectures about endoluminal stents for cervical esophagus and esophagogastric junction, and selection of stents for gastric lesions were presented. Management of upper GI bleeding (UGIB) was another highlighted session including a summary of current guidelines by session chair and two talks about conventional and new endoscopic hemostasis techniques. In addition, many innovative video cases for managements of stricture and leakage, ESD complications, refractory bleeding and huge bezoars were presented in IDEN 2012.

\section{HIGHLIGHT TOPICS IN UPPER ENDOSCOPY}

In this highlighted section of the upper GI tract, we invited several outstanding review articles to disseminate clinical excellence into the fields. First of all, upper GI bleeding is a paramount issue that still imposes a significant clinical and economical burden globally. In the last decade, there has been significant improvement in endoscopic management owing to innovative devices and in periendoscopy care based on data from clinical trials of high quality. Several recently-published consensus reports suggested recommendation state- 
ments with objective evidence levels on the topic.-5 In this issue, Kim et al. ${ }^{6}$ focused on those consensus articles addressing the management of acute non-variceal GI bleeding. ${ }^{6} \mathrm{Au}-$ thors covered the issues of initial patient assessment and risk stratification, pre- and post-endoscopic patient care, timing of endoscopy, and prevention of recurrent bleeding. Ki and $\mathrm{Lau}^{7}$ briefly reviewed current standard of endoscopic management and provided detailed information about emerging endoscopic hemostasis methods including hemospray powder, clips with improved design such as tripclip and over-thescope clip, and finally endoscopic suturing devices. Those new techniques has not been fully validated and are not available in many parts of the world; further clinical experiences will provide usefulness of those techniques using innovative devices which can be also used for closure devices. ${ }^{8}$ Furthermore, the authors suggested that interventional radiology have advanced significantly over the past decades and it is now under study as an adjunctive method to endoscopic treatment. Chung' summarized conventional treatment modalities including injection therapy, ablative therapy, mechanical therapy, and their combination therapy, which are still most commonly used and familiar to endoscopists.

Palliative treatment using self-expandable metallic stent for malignant obstruction of esophagus has become a promising endoscopic procedure that can replace surgery for this not uncommon condition. However, long tube like structure of esophagus, and active peristalsis during swallowing make an esophageal stent move distally. Subsequent stent migration is a troublesome long-term complication of the procedure. Stenting of cervical or distal esophagus may become a frustrating procedure due to foreign body sensation for the former site, and due to uncontrolled reflux symptom for the latter site. In this issue, various designs of esophageal stents equipped with anti-migration tactics and anti-reflux apparatus were summarized to cover troublesome problems. ${ }^{10}$

Recent progression of endoscopic technique provides wider range of option to the management of SET, especially for the lesion of suspected GIST. For GIST larger than $3 \mathrm{~cm}$, it may not always necessary to do an aggressive procedure to confirm the diagnosis. Moreover, tissue sampling with fine needle aspiration or Trucut biopsy also limited diagnostic yield. Thus, complete resection of the SET might be a good choice for tissue diagnosis and for possible treatment of lesions with low risk of malignancy, if the risk of complication is low. In this issue an article summarized the endoscopic treatment of SET using standard polypectomy, various endoscopic mucosal resection techniques and enucleation technique. ${ }^{11}$ Moreover, recently published endoscopic submucosal tunnel dissection technique, which is very similar to endoscopic peroral myotomy of achalasia, is a very promising technique espe- cially for cardiac lesions. ${ }^{12}$ This procedure is highly expected to gain popularity not only as a cardiac SET resection method but also as a technique in natural orifice transluminal endoscopic surgery procedure.

Lastly in this issue, endoscopic evaluation of EGC has been reviewed. The criteria for ESD have been expanded to include tumor size limitation such as $3 \mathrm{~cm}$ for EGC with ulcer or superficial submucosal invasion. In addition, tumor infiltration into submucosal layer, or it's absolute or relative depth of invasion is another important criteria for proper selection of candidate for the fascinating ESD procedure. EUS has been expected to provide accurate tumor infiltration, i.e., for T classification of tumor, node, metastasis (TNM) staging system. Recent studies showed that EUS accuracy for candidate lesions of ESD was not much higher than white light endoscopy. ${ }^{13}$ Brief summary on this topic with typical figures were provided as examples. ${ }^{14}$

\section{CONCLUSIONS}

Endoscopic treatment for the upper GI tract is evolving continuously with new techniques and innovative devices. IDEN 2012 sessions presented up-to-date and ready-to-use clinical information. Better quality upper GI endoscopy and subsequent improved patient care is our uppermost goal of disseminating interesting and educational presentations in the meeting.

\section{Conflicts of Interest}

The author has no financial conflicts of interest.

\section{REFERENCES}

1. Kim HG. Sketch of International Digestive Endoscopy Network 2012 meeting: overview. Clin Endosc 2012;45:211-213.

2. Barkun AN, Bardou M, Kuipers EJ, et al. International consensus recommendations on the management of patients with nonvariceal upper gastrointestinal bleeding. Ann Intern Med 2010;152:101-113.

3. Sung JJ, Chan FK, Chen M, et al. Asia-Pacific Working Group consensus on non-variceal upper gastrointestinal bleeding. Gut 2011;60:1170-1177.

4. Laine L, Jensen DM. Management of patients with ulcer bleeding. Am J Gastroenterol 2012;107:345-360.

5. Hwang JH, Fisher DA, Ben-Menachem T, et al. The role of endoscopy in the management of acute non-variceal upper GI bleeding. Gastrointest Endosc 2012;75:1132-1138.

6. Kim SY, Hyun JJ, Jung SW, Lee SW. Management of non-variceal upper gastrointestinal bleeding. Clin Endosc 2012;45:220-223.

7. Ki EL, Lau JY. New endoscopic hemostasis methods. Clin Endosc 2012; 45:224-229.

8. ASGE Technology Committee, Banerjee S, Barth BA, et al. Endoscopic closure devices. Gastrointest Endosc 2012;76:244-251.

9. Chung IK. How can we maximize skills for non-variceal upper gastrointestinal bleeding: injection, clipping, burning, or others? Clin Endosc 2012;45:230-234.

10. Shim CS. Esophageal stent for cervical esophagus and esophagogastric junction. Clin Endosc 2012;45:235-239.

11. Kim GH. Endoscopic resection of subepithelial tumors. Clin Endosc 2012;45:240-244. 
12. Inoue $\mathrm{H}$, Minami $\mathrm{H}$, Kobayashi $\mathrm{Y}$, et al. Peroral endoscopic myotomy (POEM) for esophageal achalasia. Endoscopy 2010;42:265-271.

13. Choi J, Kim SG, Im JP, Kim JS, Jung HC, Song IS. Endoscopic prediction of tumor invasion depth in early gastric cancer. Gastrointest Endosc
2011;73:917-927.

14. Kim SG. Estimation by gross findings in early gastric cancer. Clin Endosc 2012;45:245-247. 